\title{
Impact of Compaction Delay on the Engineering Properties of Cement Treated Soil.
}

\author{
Habeeb Adedeji Quadri ${ }^{1}$, Olabambo Adeyinka Adeyemi ${ }^{2}$, \\ Bunshiya G. Bobzom ${ }^{3}$ \\ 1, 2, 3 (Highway Division, Road Research Department, Nigerian Building and Road Research Institute (NBRRI), \\ Ota, Ogun State, Nigeria.
}

\begin{abstract}
In a bid to harness some of our local soils at the expense of expensive good quality materials for geotechnical and highway construction gave rise to this study; i.e impact of compaction delay on cement treated soil. Cement was chosen as stabilizer following its efficiency as it improves the mechanical properties of soil .The natural soil sample was obtained manually from a borrow pit that has been left fallow for a long time at a depth of about $1 \mathrm{~m}$. The sample was thereafter divided into 4 portions where a portion being natural soil (untreated) and 3 other portions treated/stabilized with cement at 3\%, 5\%, and 8\% by weight of soil were subjected to laboratory analysis (Natural Moisture Content, Atterberg Limits, Particle Size Analysis, Compaction (West African Standard \& Standard Proctor), California Bearing Ratio (CBR), Unconfined Compressive Strength test) in order to determine their engineering properties. But during compaction, the treated samples were delayed for 0,1,2,3 hours respectively in order to determine effect of compaction delay on the samples. The residual lateritic soil was classified based on AASHTO and USCS classifications. The residual lateritic soil was classified as A-7-6(7) according to AASHTO and CL according to USCS. Specimens treated with maximum $8 \%$ cement and compacted with no delays at energy levels of SP and WAS yielded average 7 day UCS values of $1660 \mathrm{KN} / \mathrm{m}^{2}$ and $2145 \mathrm{KN} / \mathrm{m}^{2}$ respectively. The average UCS value of specimen compacted using $S P$ compactive effort is lower than the conventional $1720 \mathrm{KN} / \mathrm{m}^{2}$ criterion for adequate cement stabilization. The CBR values of cement treated specimens at $8 \%$ cement stabilization with no delays recorded for the two compactive efforts of SP and WAS are $90 \%$ and 180\% respectively. The compaction and the strength characteristics of the cement stabilized lateritic soil specimens compacted at the two energy levels decreased with increase in compaction delays. At $8 \%$ cement content and maximum compaction delay of 3hours, losses of $12 \%, 23 \%, 31 \%$ and $20 \%$ in MDD, OMC, UCS and CBR respectively were recorded for specimens prepared at energy level of SP, while losses of 10\%,20\%,32\% and 39\% in MDD,OMC,UCS and CBR respectively were recorded for specimens prepared at energy level of WAS.
\end{abstract}

Keywords: UCS (Unconfined Compressive Strength), CBR (California Bearing Ratio), MDD( Maximum Dry Density), OMC (Optimum Moisture Content),SP ( Standard Proctor), WAS(West African Standard)

\section{Introduction}

Increased costs associated with the use of high quality materials led to the need for local soils to be used in geotechnical and highway construction [1]. Often however, high water content and low workability of these soils pose difficulties for construction projects. Frequently, additives such as lime, cement, fly ash, limecement-fly ash admixture, cement kiln dust, emulsified asphalt, Geofiber, and Polymer stabilizers are used to improve their engineering properties. The choice and effectiveness of an additive depends on the type of soil and its field conditions. Nevertheless knowledge of mechanistic behavior of treated soil is equally important as selecting the stabilizer [1].

Portland cement is the most important hydraulic cement utilized extensively in various types of cement stabilization of lateritic soils. Cement acts as a binder and provides the much desired hardening and strengthening properties. The addition of cement also increases compressive strength, the resistance of lateritic soils to freezing and thewing, wetting and drying. It also affects the particle size of fine particles [2].

The beneficial effects of cement on the performance of soils have been widely documented [3] [4] [5] [6]. Cement treatment leads to improvement in the mechanical properties of soils. However, the findings of different researchers on the role of Portland cement on compacted properties as well as strength and modulus have not been entirely consistent. For example, [3] and [7] reported cement treatment increased cohesion while internal friction angle remained constant. On the other hand, [5] stated that internal friction angle increased significantly. Some studies have indicated that at very low cement contents, improvement in strength is due to an increase in friction angle rather than cohesion [8] [9]. Research has also shown that cohesion increases with curing time while friction angle remains constant [10] [11] [9]. [9] reported that cement treated soils exhibit brittle types of failure at low confining pressure i.e Mohr-Coulomb failure envelope for cement treated soils is curved. 
Conventionally, Portland cement has appreciably improved the properties of the soil [12] [13] [14] [15] [16] [17]. [12] also stated that cement stabilized samples exhibited the highest curved strength when compared with lime and some mixture of both. [17] also established that $4 \%$ cement can be recommended as an optional content to stabilize soil from parts of Northern Nigeria.

[12] noticed an increase in the compressive strength of lateritic soils with cement content. [16] stated that full-depth reclamation and cement stabilization enabled significant volumes of in-place granular materials to be reclaimed and strengthened while allowing for the installation of a woven geotextile and sand drainage system over a wetted-up subgrade in a more cost-effective and sustainable construction manner.

Interestingly, compaction delays have been shown to affect some properties of lime stabilized soil [18] [19] but much have not been stated regarding the influence of compaction delay on CBR and UCS of cement stabilized yellowish brown tropical soil. Compaction delays have been shown to affect certain properties of lateritic soil-lime mixtures [18] [19]. This work investigates the effects of compaction delays on the properties of cement stabilized lateritic soil. Results from the study are used to predict the compaction and strength properties of the stabilized soil based on variables that include time delay.

\section{Materials And Methods}

The natural soil sample was obtained manually from a borrow pit that has been left fallow for a long period of time at a depth of about $1 \mathrm{~m}$ and was taken to Geotechnical Laboratory where several tests were performed on it.

Following the collection of sample from the pit, the sample was divided into four portions where a portion being the natural soil (untreated) was subjected to laboratory analysis in order to determine its geotechnical engineering properties. The three other portions treated/stabilized with $3 \%, 5 \%$, and $8 \%$ cement by weight of soil respectively were also made to undergo the same laboratory analysis to determine their geotechnical engineering properties. The tests conducted included Natural Moisture Content, Atterberg Limits, Particle Size Analysis, Compaction (West African Standard \& Standard Proctor), California Bearing Ratio (CBR), Unconfined Compressive Strength test. But during compaction, the treated samples were delayed for $0,1,2,3$ hours respectively in order to determine impact of compaction delay on engineering properties of the samples. The samples were also classified based on AASHTO Classification and USCS Classification.

These tests were conducted for the natural soil in accordance with [20] and the stabilization tests were done in accordance with [21] and [22].

Below are detailed results of all laboratory tests.

\section{Results And Discussion}

\subsection{Test Result of Natural Soil}

The preliminary tests were performed for the identification of the properties of the laterite without the addition of cement. Furthermore the results of the natural soil are summarily tabulated in Table 1.

Table 1. Test Result of Natural Soil

\begin{tabular}{|l|l|}
\hline PROPERTY & QUANTITY \\
\hline Natural moisture content, $\%$ & 7.1 \\
\hline Liquid limit, $\%$ & 44 \\
\hline Plastic limit, $\%$ & 24 \\
\hline Plasticity index, $\%$ & 20 \\
\hline Linear shrinkage, $\%$ & 9.5 \\
\hline Percentage passing BS No 200 sieve & 52 \\
\hline Group Index & 7 \\
\hline AASHTO Classification & A-7-6 \\
\hline USCS Classisfication & CL \\
\hline MDD (Stan.Proctor),mg/m ${ }^{3}$ & 1.84 \\
\hline OMC (Stan. Proctor), $\%$ & 19.1 \\
\hline MDD (West african stan.),mg/m ${ }^{3}$ & 1.89 \\
\hline OMC (West African Stan.), $\%$ & 15.7 \\
\hline UCS(Stan.proctor),KN $/ \mathrm{m}^{2}$ & 405 \\
\hline USC(West African Stan.),KN/m ${ }^{2}$ & 600 \\
\hline CBR(Stan.Proctor)\% & 8 \\
\hline CBR (West African Stan.), $\%$ & 13 \\
\hline Colour & Reddish-Brown \\
\hline
\end{tabular}




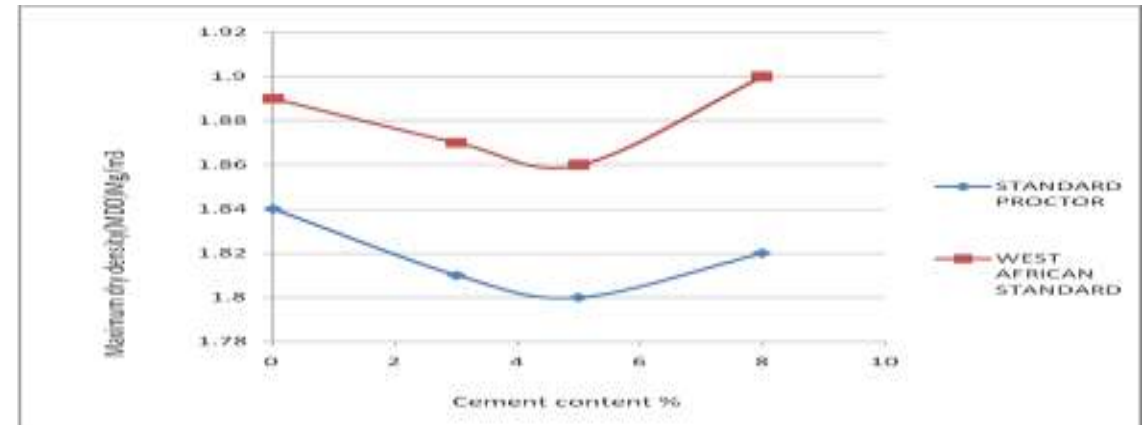

Fig1 Variation of MDD of treated soil with cement content at no compaction delay

\subsection{Result of Maximum Dry Density, Optimum Moisture Content, Unconfined Compressive Test and California Bearing Ratio}

Fig 2 shows the result and variation obtained from Maximum Dry Density for both Standard Proctor and West African Standard at 3\%, 5\%,8\% at 0,1,2,3, hours delay respectively.

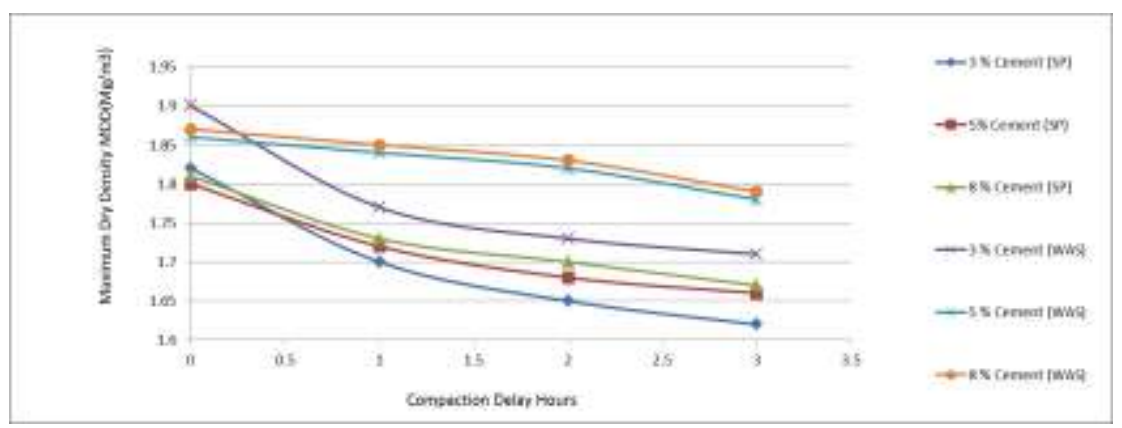

Fig 2 Variation of MDD of cement treated soil with compaction delay

Fig 3 shows the result obtained from Optimum Moisture Content for both Standard Proctor and West African Standard at 0\%,3\%, 5\%,8\% cement content respectively.

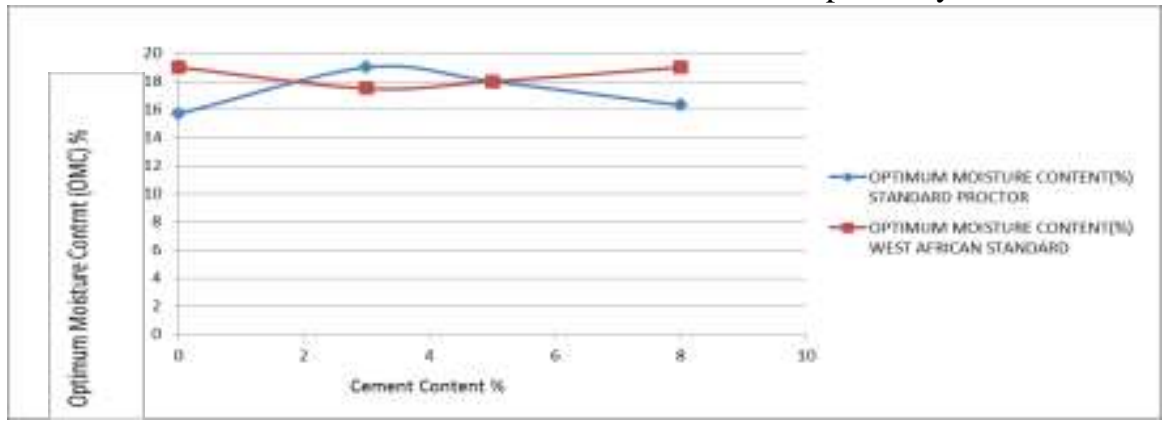

Fig3 Variation of OMC of treated lateritic soil with cement content at no compaction delay

Fig4 shows the result and variation obtained from Optimum Moisture Standard for both Standard Proctor and West African Standard at 3\%,5\%,8\% at 0,1,2,3, hours delay respectively.

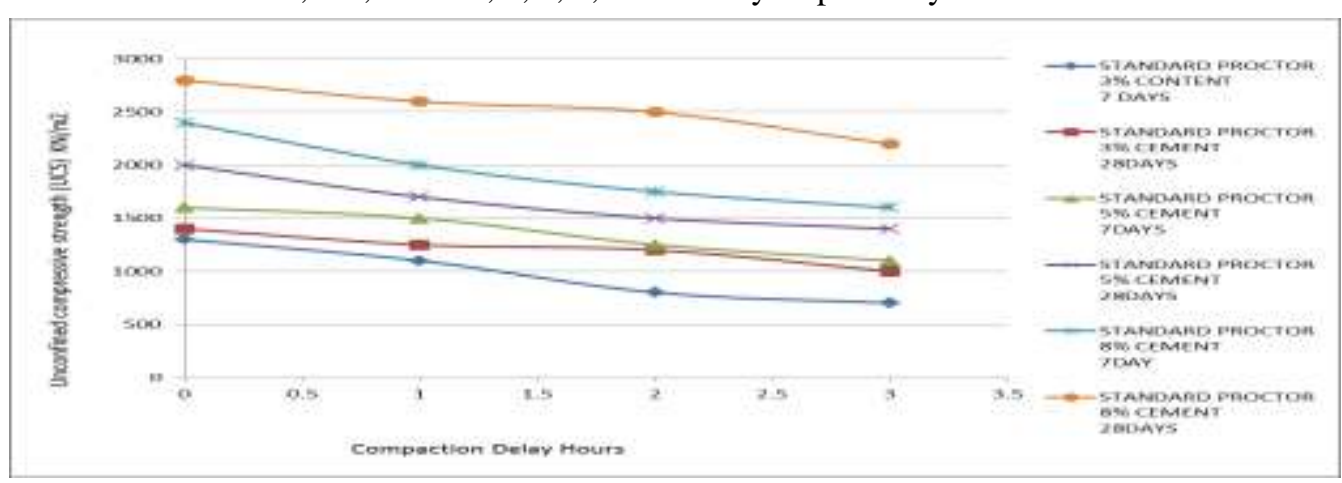

Fig 4 Variation of OMC of cement treated lateritic soil with compaction delay for West African Standard and Standard Proctor 
Fig 5 shows the result and variation obtained from Unconfined Compressive Strength for both Standard Proctor and West African Standard at 7 days and 28 days at 0\%, 3\%, 5\%, 8\%, cement content respectively.

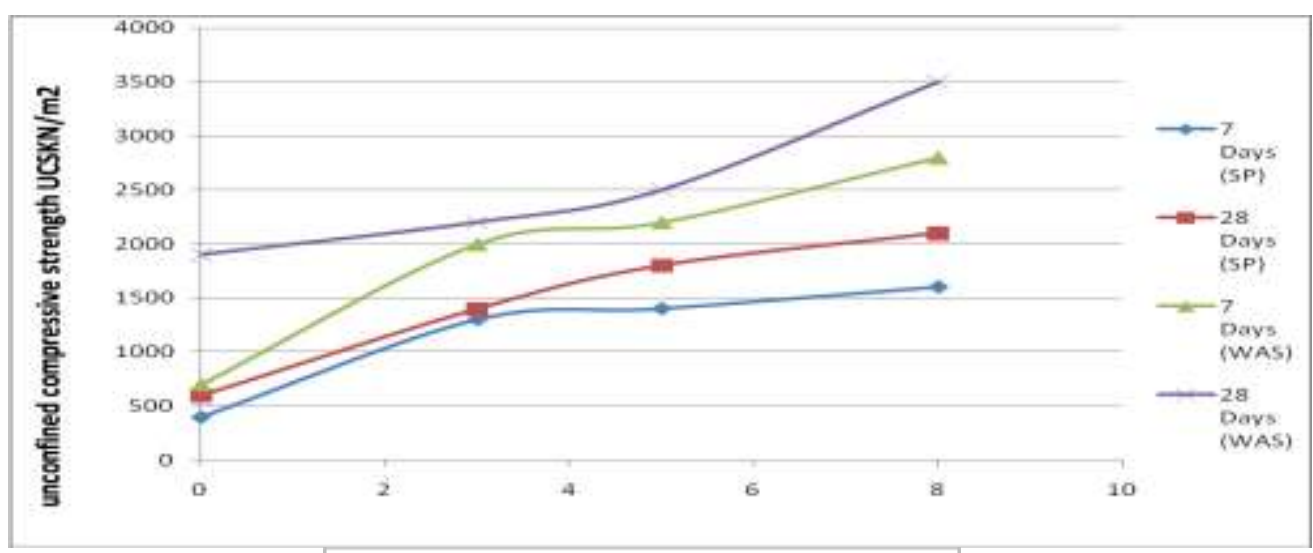

Cement Content \%

Fig5 Variation of Unconfined Compressive Strength for both Standard Proctor and West African Standard at $0 \%, 3 \%, 5 \%, 8 \%$, cement content respectively.

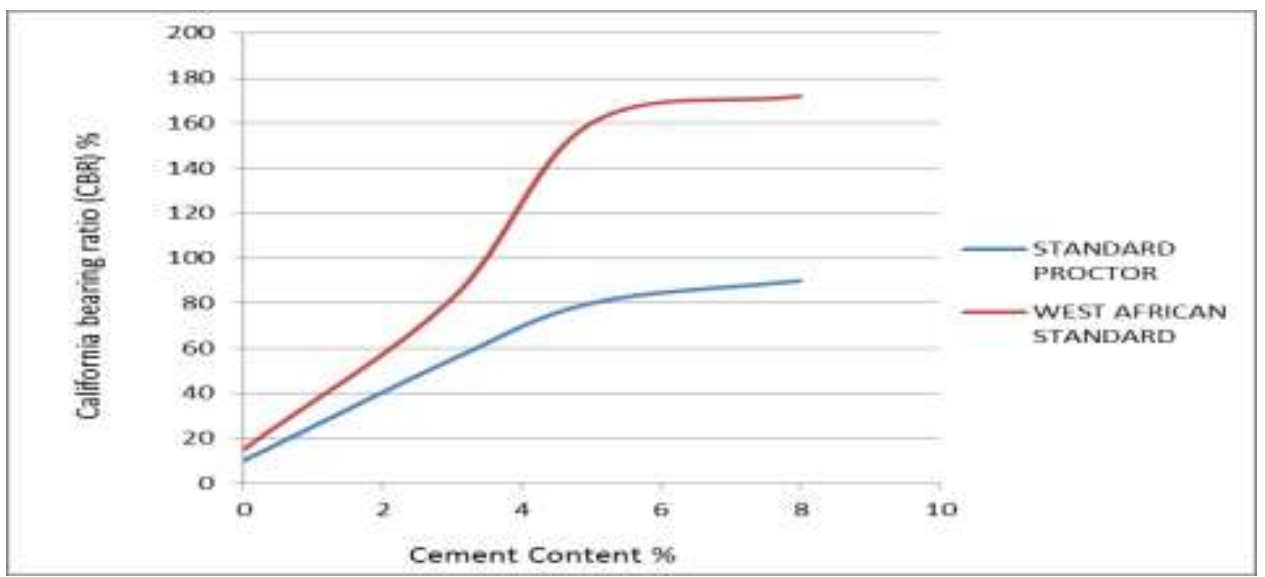

Fig 6 Variation of CBR of treated lateritic soil with cement content at no compaction delay

Fig 7 shows the result and variation obtained from Unconfined Compressive Strength for Standard Proctor only at $3 \%, 5 \%, 8 \%$, cement content at 7 days and 28 days at $0,1,2$, and 3 , delay hours respectively.

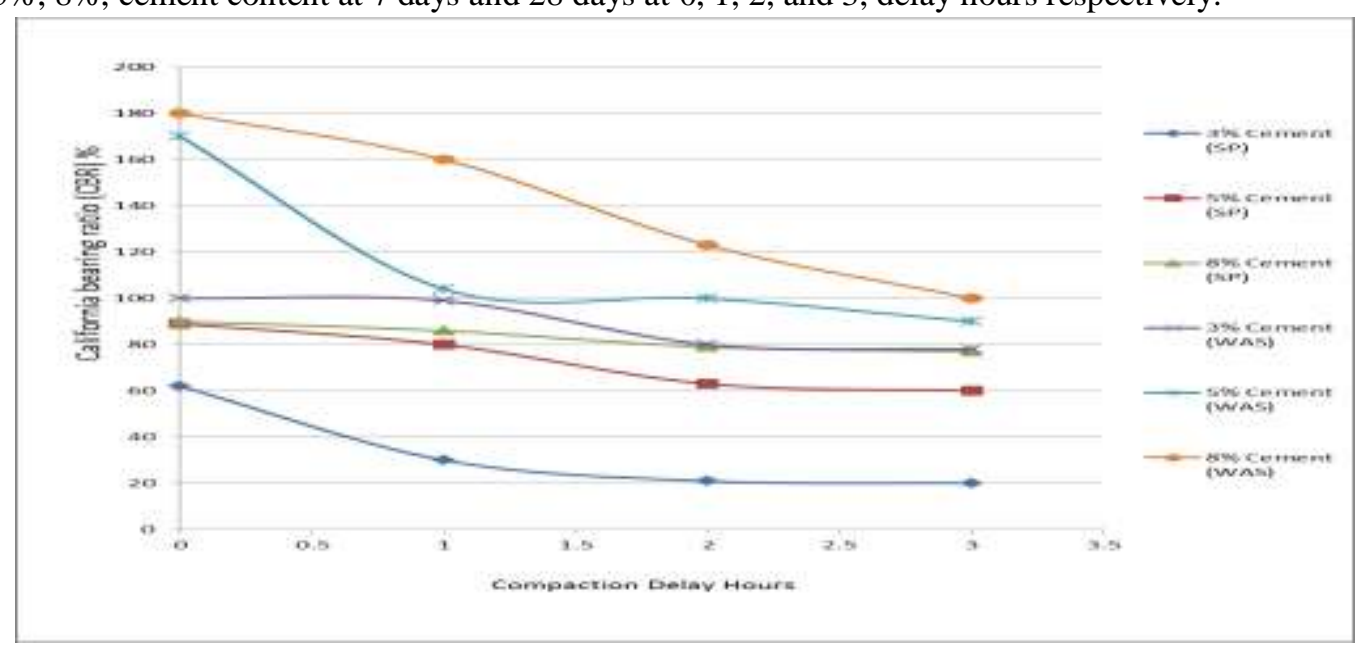

Fig 7 Variation of UCS of treated soil with compaction delay (STANDARD PROCTOR)

Fig 8 shows the result and variation obtained from Unconfined Compressive Strength for West African Standard only at 3\%,5\%,8\%, cement content at 7 days and 28 days at $0,1,2,3$ delay hours respectively. 


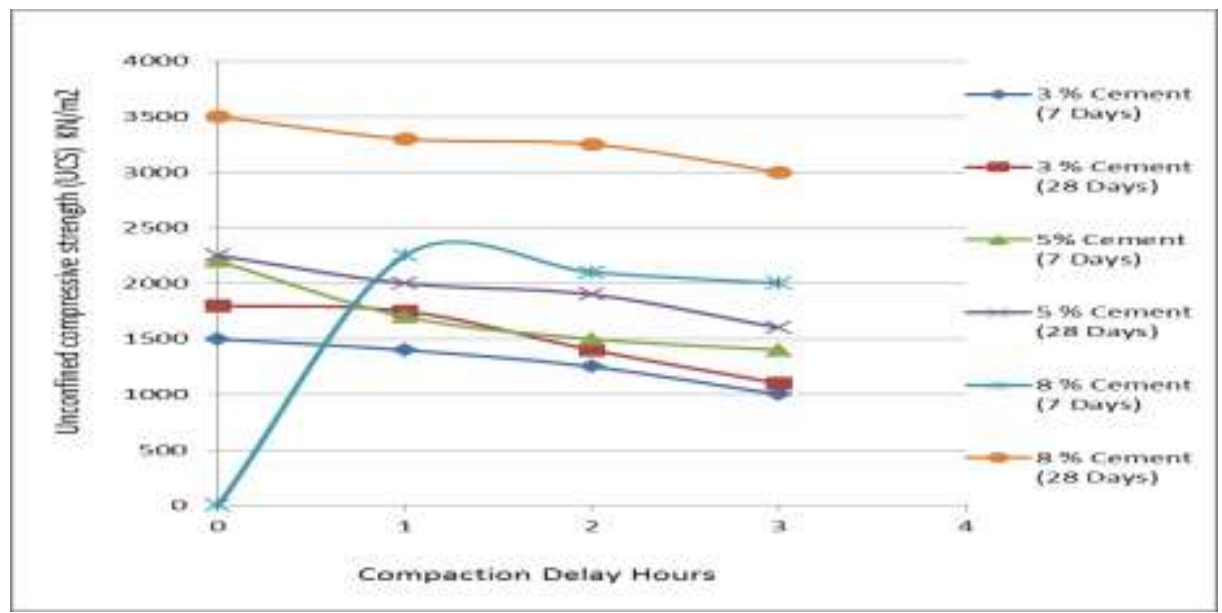

Fig 8 Variation of UCS of cement treated lateritic soil with compaction delay (WEST AFRICAN STANDARD)

Fig 9 shows the result and variation obtained from California Bearing Ratio for both Standard Proctor and West African Standard at 3\%,5\%,8\% at 0,1,2,3, hours delay

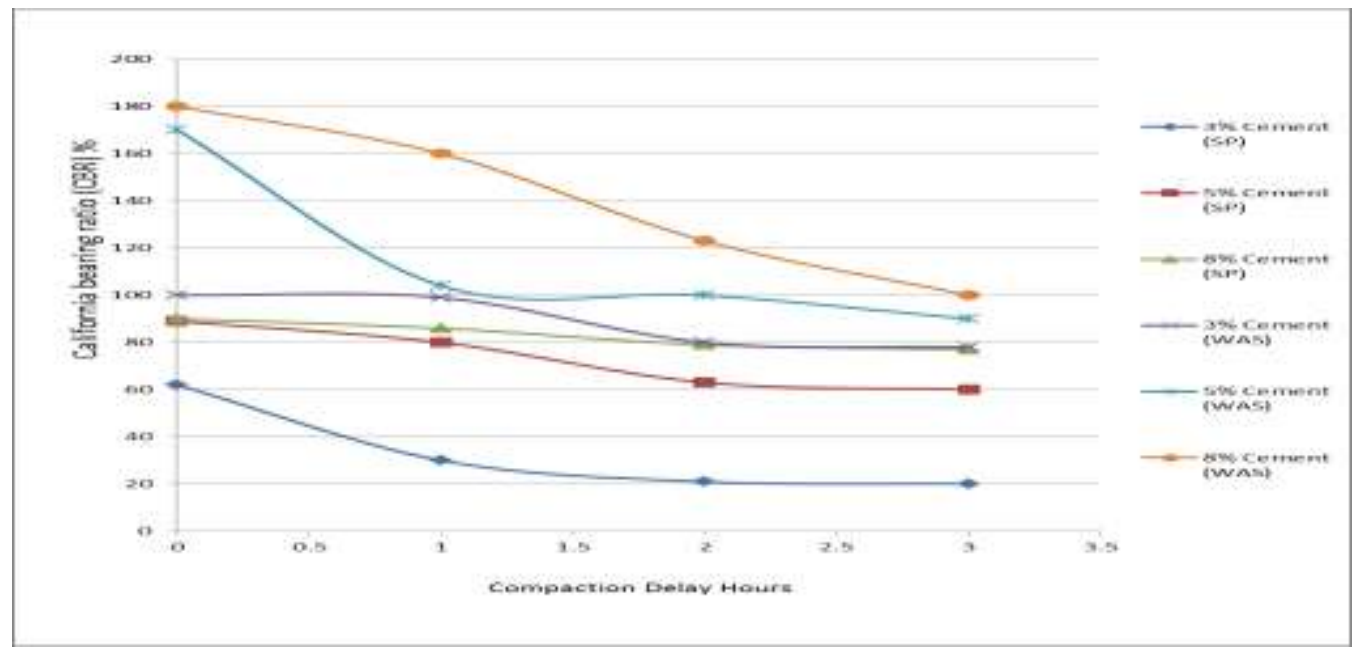

Fig 9 Variation of CBR of cement cement treated lateritic soil with compaction delay

\subsection{DISCUSSION}

\subsection{COMPACTION CHARACTERISTICS}

Maximum Dry Density: The effect of cement content on the Maximum Dry Density (MDD) of lateritic soil at no compaction delay for the SP and WAS compacted efforts is shown in Fig.1, while the MDD for the natural soil is presented in Table 1. Generally, MDD decreased to minimum values at 5\% cement content and increased with higher cement content for the specimens compacted at the two energy levels. The initial decrease in MDD was due to the presence of large, low density aggregates of particles. Above 5\% cement content, the MDD increased because the voids within the coarse aggregates were filled with cement particles with specific gravity of 3.15 .

The influence of compactive efforts and compaction delays on the MDD of lateritic soil-cement mixtures is shown in Fig. 2. The MDD of specimens for the compactive efforts used decreased with increase elapsed time after mixing. This might not be unconnected to fact that dry density of soil increases with increase in water content until it gets to maximum dry density at optimum moisture content after which the dry density continues to decrease with increase in water content. So the water needed for the initial increase in dry density would have been escaped into the air following compaction delays.

Optimum Moisture Content: The variation of Optimum Moisture Content (OMC) of stabilized lateritic soil with cement content for the two compactive efforts used at no compaction delay is shown in Fig.3. The OMC for the natural soil with respect to the two compactive efforts used are shown in Table 1. For specimens 
compacted at the energy of the SP, the initial decrease in OMC recorded may be due to self-desiccation of the water used. When no water movement to or from cement paste is permitted, the water is used up in the hydration reaction until too little is left to saturate the solid surfaces and hence the relative humidity within the paste decreases. The process described above might have affected the reaction mechanism of the stabilized lateritic soil. The range of samples compacted at the energy levels of WAS and SP with cement content, conformed to the increasing OMC/decreasing MDD, and decreasing OMC/increasing MDD patterns (see Figs. 1 and 3). It was observed that the WAS at 3\% cement content was higher in OMC than in the SP. This is not in agreement with the trend earlier reported by [18] for the same type of soil. Test variability might be responsible for the result obtained.

The effect of compactive efforts and compaction delays on the OMC of soil-cement mixtures are shown in Fig.4. Generally, it was observed that OMC decreased with increase in compaction delays. The specimens with $3 \%$ cement content compacted at the energy level of the SP had the largest loss in OMC of $26 \%$ at the end of a three hour elapsed time after mixing. This may not be unconnected with the lower hydration produced in the 0-3\% cement content range at no compaction delay. The losses in OMC of specimens recorded at $8 \%$ cement content and a maximum of three hours compaction delay for the SP and WAS compactive efforts are $23 \%$ and $20 \%$, respectively. The decrease in OMC of cement treated specimens with increase in compaction delays as shown in fig4 is mainly due to the fact that, why hydration (primary reaction) is expected to decrease continuously with increase in time, the secondary reaction which is pozzolanic in nature results in ion exchange that modifies the clay structure of the soil, thus, reducing its plasticity index (PI) and OMC.

\subsection{STRENGTH CHARACTERISTICS}

The strength criterion used in selecting materials for base course is the stability measured in terms of the California Bearing Ratio (CBR) and Unconfined Compressive Strength (UCS) which are indirect tests for evaluating strength characteristics of paving materials. Although the most popular procedure is the UCS, it is however, not necessarily the most appropriate test for all cases. The use of the CBR test for determination of cement requirements is probably due to the wide use of the test for pavement design purposes in tropical areas [23]. However, one of the main difficulties in the use of this test is the uncertainty of choosing the curing procedure which is the most representative of the field conditions expected for tropical environments and which value of CBR is considered for the finished stabilized layer. According to [12], cement-stabilized soils are usually evaluated by UCS test, but CBR testing is employed in evaluating lime-stabilized soils due to the differences in their hardening characteristics. For the purpose of this study the soil-cement mixture prepared was evaluated using the UCS and CBR criteria.

The improvements in the UCS and CBR due to the addition of cement at no compaction delay for the two compactive efforts are shown in Figs.5 and 6, respectively, while Figs. 7, 8, 9, show the influence of compaction delays on UCS and CBR values. Cement-stabilized soils harden quite rapidly, particularly at high ambient temperatures, which are common in the tropics. The result of soil-cement reaction is the improvement of the engineering properties of the natural soil.

Unconfined Compressive Strength: Figure 5 shows that the UCS increased with curing period at $0 \%$ cement content. This gain in strength might not be unconnected to hydration reaction that takes place whenever cement comes in contact with water. When water reacts with cement in the specimens, it bonds the components together; hence robust stone-like specimens are created. Consequently, judging from the low durability indicated by the resistance to loss in strength of $34 \%$ and $32 \%$ for UCS specimens compacted at the energy levels of the SP and WAS respectively, it can be taken that $8 \%$ cement-stabilization is not adequate for lateritic soil used in this study.

\section{Conclusion}

The residual lateritic soil used in this study was classified as A-7-6 (7) and CL as according to[24]. Specimens treated with maximum $8 \%$ cement and compacted with no delays at the energies of the SP and WAS yielded average 7 day UCS values of $1660 \mathrm{kN} / \mathrm{m}^{2}$ and $2145 \mathrm{kN} / \mathrm{m}^{2}$, respectively. For specimens compacted using the SP compactive effort the average UCS value is lower than the convetional $1720 \mathrm{kN} / \mathrm{m}^{2}$ criterion for adequate cement stabilization and it implies that the $7 \%$ cement content prescribed for the stabilization of A-7 soil by [22] is not adequate for the lateritic soil used in the study. The conventional requirement for adequate cement stabilization was met by specimens compacted at the energy of the WAS. However, a cause for concern is the low durability measured by way of resistance to loss in strength of UCS specimens immersed in water. The CBR values recorded for the two compactive efforts at no delay range between $60 \%$ and $180 \%$ with the specimens compacted at the energies of the SP and WAS satisfying the prescribed $80 \%$ minimum CBR value for base course as according to [22] except for 3\% cement stabilization compacted at energy level of SP whose value was $60 \%$.The maximum values for the two compacted energy levels were recorded at $8 \%$ cement 
stabilization i.e $90 \%$ and $180 \%$ for SP and WAS respectively. It can be concluded that the $8 \%$ cementstabilized lateritic soil is adequate for base course at the energy levels considered in this study.

The compaction and strength characteristics of the cement-stabilized lateritic soil specimens compacted at the two energy levels decreased with increase in compaction delays. A maximum delay of 1 hour and 2 hours for specimens compacted at the energies of the SP and WAS, respectively, are all that can be tolerated. At $8 \%$ cement content and a maximum compaction delay of 3 hours, losses of $12 \%, 23 \%, 31 \%$ and $20 \%$ in MDD, OMC, UCS and CBR, respectively were recorded for specimens prepared at the energy level of the SP, while losses of $10 \%, 20 \%, 32 \%$ and $39 \%$ in MDD, OMC, UCS and CBR, respectively, were recorded for specimens prepared at the energy level of the WAS.

\section{References}

[1] Muhunthan, B and Sariosseiri, F (2008). "Interpretation of Geotechnical Properties of Cement Treated Soils" Washington State Transportation Centre (TRAC). WA-RD 715.1

[2] Bello, A.A. (2011). 'Influence of Compaction Delay on CBR and UCS of Cement Stabilized Lateritic Soil. The Pacific Journal of Science and Technology, Volume 12, Number 2, 87-96

[3] Balmer, G.G. (1958). Shear strength and elastic properties of soil-cement mixture under triaxial loading. Portland cements Association Research and Development Laboratories.

[4] Mitchell, J.K. (1976), 'The properties of Cement-stabilized soils" Proceeding of Residential Workshop on Materials and Methods For Low Cost Road, Rail, and Reclamation works, 365-404, Leura, Australia, Unisearch Ltd.

[5] Uddin, K., Balasubramaniam, A.S., and Bergardo, D.T. (1997). "Engineering behaviours of cement-treated Bangkok soft clay", Geotechnical Engineering Journal, (28)1, 89-119.

[6] Lo, S.R., and Wardi, S.P.R, (2002). "Strength and dilatancy of a stabilized by a cement and fly ash mixture. " Canadian Geotechnical Journal, 39(1), 77-89.

[7] Clough, G.W., Sitar, N., Bachus, R.C., and Shafii-Rad, N. (1981). "Cement sands under static loading" Journal of The Geotechnical Engineering Division, ASCE, 107 (GT6). 799-817

[8] Rocha, M., Folgue, J., and Esteves, V.P. (1961). "The application of cement stabilized soils in the construction of earth dams" Fifth International Conference on Soil Mechanics and Foundation Engineering. Paris, France.

[9] Abboud, M.M. (1973). Mechanical properties of cement-treated soils in relation to their use in embankment construction, Ph.D dissertation, University of California, Berkeley, CA.

[10] Nash, J.K.T.L., Jardine, F.M., and Humphrey, J.D., (1965). "The economic and physical feasibility of soil-cement dams. " Proceedings of the Sixth International Conference on Soil Mechanics and Foundation Engineering, 2, 517-521, Montreal, Canada.

[11] Wissa, A.E.Z., Ladd, C.C., and Lanbe, T.W. (1965). "Effective stress-strength parameters of stabilized soils. " Proceedings of the Sixth International Conference on Soil Mechanics and Foundation Engineering, Montreal, Canada.

[12] Ola, S.A. (1975). "Stabilization of Nigerian Laterite Soils with Cement Bitumen and Lime" Proceedings of the Sixth Regional Conference for Africa on Soil Mechanics and Foundation Engineering. Durban, South Africa. 1: 145-152

[13] Ola, S.A. (1983). "Geotechnical Properties and Behaviour of Some Nigerian Lateritic Soils".'In: S.A. Ola. Tropical Soils of Nigeria in Engineering Practice. A.A. Balkema: Rotterdam, The Netherlands, 61-84.

[14] Osula, D.O.A. (1989). "Evaluation of Admixture Stabilization for Problem Laterite" Journal of Transportation Engineering. 115 (6): $674-687$

[15] Scullion, T. and Harris, P. (1998). "Forensic Evaluation of Three Failed Cement Treated Base Pavements" Transportation Research Record. 1611: 10-18.

[16] Berthelot, C., Marjerison, B., Gorlick, R., Podborochynski, R., Fair, J., and Stuber, E. (2009). 'Field Investigation of Granular Base Rehabilitation Project Incorporating Woven Geotextile Seperation Layer, Sand, and Cement Stabilization'. Can. J. Civ. Eng. 36(1): $14-25$

[17] Gadzama, E.W. (2009). "Evaluation of Soil Samples From Federal University of Technology, Yola Site" Nigerian Journal Of Engineering. 15(2): 80-88.

[18] Osinubi, K.J. (1998). "Influence of Compaction Delay on the Properties of Cement-Stabilized Lateritic Soil". Journal of Engineering Research. 6 (1): 13-26.

[19] Osinubi, K.J. and Nwaiwu, C.M.O. (2002). "Compacted Lateritic Soils as Hydraulic Barriers in Waste Containment Systems" Proceedings of the Fouth International Congress on Environmental Geotechnics. Brazil. 1, 225-230.

[20] B.S. 1377, Methods of testing soil for civil engineering purposes, British Standards Institute London, 1990.

[21] B.S. 1924, Methods of Testing for Stabilized soils, British Standards Institute London, 1990.

[22] Nigerian General Specification. Roads and Bridge Work, Federal Ministry of Works, Lagos, Nigeria, 1997.

[23] Transport and Road Research Laboratory (TRRL), 1977. '’TRRL Laboratory Report, Issues 1119-1132.

[24] Annual Book of ASTM Standards, 1992, Vol. 11.01 